\title{
RSP Revisitada Machado de Assis funcionário público
}

Texto publicado na RSP de out/dez. 1981 (Ano 38, v. 109, n. 4)

Raymundo Magalhães Jr.

Joaquim Maria Machado de Assis, uma das maiores figuras do mundo literário brasileiro do século passado e do início deste século, teve duas carreiras paralelas, a de homem de letras e a de burocrata. Na primeira iniciou-se mais cedo, quando, apenas um adolescente de pouco mais de 15 anos, publicou um soneto - por sinal bem ruinzinho - no Periódico dos Pobres, a 3 de outubro de 1854. Nascido no morro do Livramento, perto da Gamboa e do Saco do Alferes, a 21 de junho de 1839, deu mostras de impressionante precocidade, ao assinar um Soneto, no mesmo jornalzinho. Nota-se que, nessa época, o Rio de Janeiro ainda não tinha sequer iluminação a gás - só contratada pelo governo imperial em 1859 - nem sabia ainda o que fossem estradas de ferro. Seu ingresso no serviço público só se daria quase treze anos depois dessa estréia literária, que em nada fazia prever o grande escritor que viria a ser. E isto se deu a 8 de abril de 1867, com a sua nomeação para "ajudante do diretor de publicação do Diário Oficial", então subordinado ao Ministério da Fazenda, durante o $22^{\circ}$ gabinete ministerial da monarquia, chefiado pelo então deputado-geral Zacarias de Góis e Vasconcelos. 
Entre essas duas datas do primeiro escrito publicado na imprensa e a admissão no serviço público do Império, Machado de Assis realizara uma brilhante carreira jornalística e literária. Colaborara nas revistas A Marmota Fluminense, O Espelho, A Semana Ilustrada, O Futuro, Jornal das Famílias, e nos jornais Diário do Rio de Janeiro, Correio Mercantil, O Paraíba, Imprensa Acadêmica (de São Paulo), Correio da Tarde e outros. Publicara seus primeiros trabalhos em livro: a peça teatral Desencantos, o volume intitulado Teatro (contendo as comédias $\mathrm{O}$ caminho da porta e $\mathrm{O}$ protocolo), as comédias Quase ministro e Os deuses de casaca (em volumes separados) e, ainda, seu primeiro livro de versos, intitulado Crisálidas. Além disso, exercitara a sua pena como tradutor de peças teatrais para a Companhia Furtado Coelho, numa delas, O barbeiro de Sevilha, de Beaumarchais; fizera parte da equipe de tradutores de O Brasil pitoresco, obra em dois grandes volumes, escrita por Charles Ribeyrolles e ilustrada pelo fotógrafo Victor Frond; traduzira a obra anônima Queda que as mulheres têm pelos tolos e, ainda, o romance de Victor Hugo, Os trabalhadores do mar, publicado em folhetim no Diário do Rio de Janeiro. O que é mais singular é que Machado de Assis, embora sendo autodidata, não apenas traduzia correntemente do francês para o português, mas ainda escrevia diretamente em francês versos bastante razoáveis, principalmente paródias cômicas de poesias de Victor Hugo e de Alfred de Musset. A publicação das Crisálidas, em 1864, colocara seu nome em evidência, como um dos mais promissores entre os novos poetas brasileiros.

Como jornalista, ligado ao Partido Liberal, pois o Diário do Rio de Janeiro, para onde entrou em 1860, antes dos 21 anos, era antes de tudo um órgão partidário, comprometido com aquela agremiação a mais inquieta, progressista e turbulenta da monarquia (de sua ala extremada tinham irrompido as revoluções em 1842, em Minas e São Paulo, e a de 1848 em Pernambuco) - Machado de Assis várias vezes a tacara Zacarias de Góis e Vasconcelos, que ainda não se desligara inteiramente de seus antigos vínculos com o Partido Conservador. Mas, quando Zacarias adotou a posição liberal, mudou de atitude, o que não lhe foi difícil, pois seus ataques não tinham sido extremados ou agressivos. Foi o próprio gabinete de Zacarias que, a 16 de março de 1867, fez condecorar Machado de Assis com a insígnia de cavaleiro da Ordem da Rosa, destinada a premiar o mérito literário e artístico. E, vinte e dois dias depois, assinava, como Ministro da Fazenda, o ato que lhe assegurava o ingresso no serviço público. Neste, entrara Machado de Assis com o pé direito, pois que, pouco antes, tivera o seu valor reconhecido e oficialmente proclamado.

Que fizera ele para merecer tanto? Em primeiro lugar, esses dois fatos se verificaram em plena guerra da Tríplice Aliança (Brasil, Argentina e Uruguai) contra o Paraguai de Francisco Solano López. Além de apoiar, como jornalista, as posições do governo, Machado de Assis escreveu poesias patrióticas. Três anos antes, por ocasião da Questão Christie, já havia escrito um hino cantado nos teatros do Rio de Janeiro, em desagravo da honra nacional, ultrajada pela intervenção inglesa em nossos portos, com o apresamento de vários dos nossos navios mercantes. Além disso, durante três anos, Machado de Assis exercera, sem remuneração, a função de censor teatral, como membro do Conservatório Dramático Brasileiro, entidade particular reconhecida pelo governo. 
Machado de Assis deixou o Diário do Rio de Janeiro ao entrar para o Diário Oficial, mas continuou a atuar no jornalismo, colaborando em várias publicações sem filiação partidária declarada. Dois anos e oito meses depois de seu ingresso no serviço público, Machado de Assis se casava com a portuguesa Carolina Augusta Xavier de Novais, que chegara ao Brasil a 18 de junho de 1868, para cuidar do irmão enfermo, Faustino Xavier de Novais, poeta e jornalista, fundador e diretor de OFuturo, a revista efêmera em que o autor das Crisálidas muito colaborara em prosa $\mathrm{e}$ verso. Com o aumento de suas responsabilidades, Machado desdobrou-se em trabalhos, principalmente como tradutor. Traduziu novas peças teatrais. Traduziu como folhetim para o Jornal da Tarde o longo romance de Charles Dickens Oliver Twist, e para a revista $A$ Instrução Pública, a obra do médico e educador francês $\mathrm{T}$. Gallard, Notions d'bygiene à l'usage des instituteurs primaires, a que deu o título de Higiene para o uso dos mestres-escolas, cuja publicação se prolongou até 1874 . Em 1871, retornou à função de censor teatral, ainda uma vez sem receber qualquer remuneração. E, em abril de 1872, foi designado pelo Ministro da Marinha a fazer parte da comissão do Dicionário Marítimo Brasileiro, em substituição a Henrique César Muzzio, que, cego e em tratamento na Europa, morrera em Paris. Muzzio havia sido o secretário do Diário do Rio de Janeiro, quando Machado nele começara a trabalhar. Essa nova função era um mero "bico" e não atendia às suas necessidades mais prementes.

Mas, nesse mesmo ano, quando se achava na presidência do gabinete o visconde do Rio Branco José Maria da Silva Paranhos), notável estadista imortalizado por ter feito aprovar na Câmara e no Senado do Império a famosa "Lei do Ventre-Livre" - segundo a qual não mais nasceram escravos no Brasil - Machado de Assis conseguiu obter um cargo de primeiro oficial, ou de amanuense, do Ministério de Agricultura, Comércio e Obras Públicas, cujo ministro era, então, o deputado José Fernandes da Costa Pereira Júnior. Durante algum tempo, Machado de Assis se manteve nos dois cargos - o do Diário Oficial e o do Ministério - trabalhando primeiro neste e depois naquele, onde o expediente se prolongava noite adentro. Machado de Assis ingressou no Ministério da Agricultura, Comércio e Obras Públicas quando tinha passado dos 33 anos e já era uma figura destacada das letras brasileiras. Em 1868, José de Alencar o consagrara como a mais importante figura da crítica literária de seu tempo, ao pedir-lhe que apresentasse ao meio intelectual do Rio de Janeiro o jovem poeta Castro Alves. Em 1870, publicara os Contos fluminenses e o segundo livro de versos, Falenas. Em 1872, publicara o seu primeiro romance, Ressurreição. E, em 1873, novo livro de contos, das Histórias fluminenses. Ia ter, a partir daquela nomeação, vida mais tranqüila e segura, mas não menos laboriosa, por sua inexcedível dedicação, tanto às letras como às funções burocráticas, exemplarmente desempenhadas.

Machado de Assis era ainda chefe da $2^{a}$ Seção do Ministério da Agricultura, Comércio e Obras Públicas, quando deu um memorável parecer sobre importante assunto submetido à sua apreciação, que dizia respeito ao registro de escravos, regulado pela Lei do Ventre-Livre, de 28 de setembro de 1871. O registro tinha como finalidade manter um cadastro da população escravizada, fazer com que as crianças nascidas depois da promulgação dessa lei tivessem os nascimentos 
registrados como pessoas livres, além de outras medidas no interesse dos cativos. Aquela lei instituíra também ações de liberdade, ou causas de liberdade, propostas pelos escravos, ou em nome destes, para que objetivassem a condição de pessoas livres. Dessas ações, quando as decisões judiciais fossem contrárias a seus autores, haveria sempre a apelação ex-officio para a instância superior. Ora, um proprietário da comarca de Resende, na província do Rio de Janeiro, ganhara uma ação ordinária e, não tendo havido apelação, por parte dos escravos envolvidos no pleito, pretendia o interessado, José Pereira da Silva Porto, obter o registro desses mesmos escravos, mediante apresentação de traslado da sentença que lhe dera ganho de causa. O presidente da província do Rio de Janeiro, Francisco Xavier Pinto Lima (depois agraciado com o título de barão de Pinto Lima) achou que a situação não estava suficientemente clara e, por isso, submeteu o assunto ao exame do Ministério da Fazenda. O ministro, na época o barão de Cotejipe, decidiu que fosse ouvido o Ministério da Agricultura, Comércio e Obras Públicas, por ser deste a competência, pois lhe estavam subordinados os assuntos referentes aos escravos, cartas de alforria, manumissões, e todos os demais, exceto a cobrança das taxas de registro.

As questões suscitadas eram as seguintes:

1) Poderia o coletor de Resende inscrever na matrícula especial os escravos do cidadão José Per eira da Silva Porto, que não haviam sido matriculados em tempo hábil, isto é, no prazo determinado pela lei de 28 de setembro de 1871 ?

2) Em vista do artigo $7^{\circ}, \int 2^{\circ}$, da mesma lei - o qual estabelecia que, nas causas em favor da liberdade, haveria apelação ex-officio quando as decisões lhes fossem contrárias - produziria efeitos a sentença obtida com base no artigo 19 do regulamento da mesma lei, sem que da mesma houvesse sido interposta apelação ex-officio ou voluntária? O ministro Tomás José Coelho de Almeida pediu que fossem ouvidos os funcionários do Ministério da Agricultura, Comércio e Obras Públicas, de maior graduação e com a necessária competência para opinar sobre o assunto. E pediu também a opinião do procurador da coroa, desembargador João Evangelista de Negreiros Saião Lobato.

Os funcionários que opinaram foram os seguintes: José Diniz de Vilas-Boas, oficial da Secretaria; Augusto José de Castro e Silva, antigo diretor de Agricultura; José Pedro Xavier Pinheiro, oficial da Secretaria; Francisco Leopoldino Gusmão Lobo, chefe da Diretoria Central; e, finalmente, Joaquim Maria Machado de Assis, chefe da $2^{a}$ Seção de Agricultura. Esse episódio é, sem dúvida, um dos mais significativos da carreira de Machado de Assis, sobretudo por ter sido vitorioso o ponto de vista de um funcionário que, sem ser bacharel em direito, demonstrou grande tino jurídico, vendo o seu ponto de vista vencedor. As opiniões foram de início divergentes. Saião Lobato manifestou-se contra a concessão da matrícula. No seu entender, como não houvera apelação, também não podia haver registro. VilasBoas opinou no mesmo sentido. Mas em sentido contrário opinaram três altos funcionários: Xavier Pinheiro, Castro e Silva e, finalmente, Gusmão Lobo, que foi citado por Joaquim Nabuco, no livro Minha formação, como um adepto da causa abolicionista. Castro e Silva afirmou se tratava da "libertação de escravos que deixaram de ser matriculados, e cuja reivindicação era permitida por ação ordinária, nos termos do artigo 19 da lei 
de 28 de setembro, e que o $\operatorname{artigo~} 7^{\circ}$ se referia ao processo, aliás sumário, para a alforria por indenização do valor ou remissão". E concluía dizendo pensar que, "sendo independentes os poderes políticos do Império, ao Executivo cabia acatar as decisões do Judiciário e, conseqüentemente, ordenar ao coletor de Resende que matriculasse os escravos de José Pereira da Silva Porto."

Xavier Pinheiro fez várias considerações sobre o problema, para por fim declarar: "Examinando atentamente os papéis, cabe me dizer que, para resolvê-lo, basta considerar que duas são as ações concernentes à alforria de escravos. Em uma, a favor da liberdade, em que o autor é escravo, o processo é sumário e, quando a decisão do juiz é contrária à liberdade, haverá apelação ex-officio (artigo $7^{\circ}$ da lei no 2.040). Noutra, a favor da escravidão, em que o senhor é o autor, o processo é ordinário, e não há recurso ex-officio, sem que, no entanto, às partes seja tolhido o direito de apelar. No caso presente, a causa é ordinária, e o juiz não está na obrigação de apelar ex-officio. Os interessados, isto é, os três escravos, não recorreram da sentença, que assim passou em julgado. Resta, portanto, expedir ordens a fim de que produza os devidos efeitos".

Gusmão Lobo, pelo menos aparentemente, dava visível apoio a essa tese. Disse tratar-se de uma questão "muito grave" e alegou que era com pesar que discordava "do parecer do Sr. Procurador da Coroa". Finalmente, declarou que, "ainda que a matéria esteja largamente discutida, conviria que sobre ela dissesse o atual chefe da 2 Seção", Tal chefe, ainda em caráter interino, era Machado de Assis, que assim foi provocado a manifestar-se. Nesse processo encontram-se palavras de Gusmão Lobo que valem como um atestado de seu zelo e capacidade funcional: "Recomendo- the que o faça em prazo curto, como costuma fazer, pois trata-se de negócio pendente há quase um ano./ 15 de julho de 1876./ Gusmão Lobo". Seis dias depois, dava Machado de Assis seu magistral parecer, em que começava por declarar: " 2 a Seçãa/ Obedecendo ao despacho da Diretoria, examinei detidamente estes papéis e, à vista deles e das disposições legais, direi resumidamente o que me parece./ No art. $7^{\circ}, \int 2^{\circ}$ da lei de 28 de setembro de 1871 se diz que das decisões contrárias à liberdade, nas causas em favor desta, haverá apelação ex-officio. Pelo artigo 18 do regulamento de $1^{\circ}$ de dezembro do mesmo ano, os escravos que não forem dados à matrícula por culpa ou omissão dos senhores serão considerados libertos, salvo aos mesmos senhores o meio de provar, em ação ordinária, o domínio que têm sobre eles, e não ter havido culpa, ou omissão sua, na falta da matrícula./ Pergunta- se: Das sentenças que, na hipótese do artigo 19, forem contrárias à liberdade, cabe apelação ex-oficio?/ Minha resposta é afirmativa. Para responder de outro modo, fora preciso fazer entre os dois casos uma distinção que não existe, e que, a meu juízo, repugna ao espírito da lei”.

Em seguida, Machado de Assis começava a expor suas razões: "O argumento principal que acho nestes papéis, favorável à negativa, é que as causas de que trata o artigo 19 do regulamento não são a favor da liberdade, isto é, não são propostas pelo escravo, mas pelo senhor, a favor da escravidão, entenda-se a favor da propriedade./ Esta diferença não é radical, mas aparente e acessória. As causas do artigo 19 é certo que não as propõe o escravo, mas o senhor; não têm por objeto a libertação, mas a prova da propriedade do senhor e da força maior que deu lugar à falta de matrícula. Mas em que tal 
diversidade de origem pode eliminar o objeto essencial e superior do pleito, isto é, a liberdade do escravo?/ Importa pouco ou nada que o recurso à justiça parta do escravo ou do senhor, desde que o resultado do pleito é dar ou retirar a condição livre ao indivíduo nascido na escravidão. Acresce que, na hipótese do artigo 19, a decisão contraria a liberdade, é contrária à liberdade adquirida, anula um efeito da lei, restitui à escravidão o indivíduo já chamado à sociedade livre; neste, como no caso do artigo $7^{\circ}$ da lei, é a liberdade que perece; em favor dela deve prevalecer a mesma disposição".

Ainda não esgotara, no entanto, sua argumentação. E assim concluiu: "Na diferença entre ação sumária (artigo $7^{\circ}$ da lei) e ação ordinária (artigo 19 do regulamento) não estará, presumo eu, a razão da diferença para a aplicação do recurso de que se trata. Ser sumário ou ordinário o processo, suponho que apenas the diminui ou multiplica os trâmites, circunstância alheia ao ponto litigioso./ Outrossim, convém não esquecer o espírito da lei. Cautelosa, eqüitativa, correta, em relação à propriedade dos Senhores, ela é, não obstante, uma lei de liberdade, cujo interesse ampara em todas as suas partes e disposições. É ocioso apontar o que está no ânimo de quantos a têm folheado; desde o direito e facilidades da alforria até à disposição máxima, sua alma e fundamento. Sendo este o espírito da lei, é para mim manifesto que num caso como o do artigo 19 do regulamento, em que, como ficou dito, o objeto superior e essencial é a liberdade do escravo, não podia o legislador consentir que esta perecesse sem aplicar em seu favor a preciosa garantia indicada no artigo $7^{\circ}$ da lei./ Tal é o meu parecer, que sujeito à esclarecida competência da Diretoria. Em 21 de julho de 1876./Machado de Assis".
Mas isso não foi bastante para convencer o diretor Gusmão Lobo, que voltou a insistir em seu ponto de vista e terminou por sugerir: "A questão é grave e, dada a diversidade de pareceres, penso que deve ser submetida ao exame da ilustrada Seção dos Negócios da Justiça do Conselho de Estado, cujo esclarecido voto exercerá decisiva influência sobre o ânimo dos julgadores, concorrendo para firmar uma interpretação segura e invariável./3 de agosto de 1876./ Gusmão Lobo”. Os membros da Seção dos Negócios da Justiça do Conselho de Estado eram três juristas ilustres: o conselheiro José Tomás Nabuco de Araújo, pai de Joaquim Nabuco e antigo ministro da Justiça; Francisco de Paula Saião Lobato (visconde de Niterói), antigo magistrado e ex-ministro da Justiça; e José Ildefonso de Sousa Ramos, bacharel em direito, parlamentar do Império e também antigo ministro da Justiça. O parecer dos três ilustres homens de estado concluiu no mesmo sentido pelo qual se havia manifestado Machado de Assis. É uma peça longa, que examina minuciosamente a questão e apresenta essas conclusões:

"A lei não diz ações de liberdade, mas causas de liberdade; a lei refere-se ao objeto e não ao meio. Mas, então, a ação do artigo 19 citado devia ser sumária? Não; porque a lei só tem por fim favorecer a liberdade e não a escravidão; as exceções são só em favor da liberdade; a escravidão fica como antes dela, no princípio ou regra de direito comum, que é a ação ordinária. Portanto, o argumento legal em que se apóia a afirmativa é o argumento a simile, que consiste em aplicar a um caso não previsto na lei a regra estabelecida para caso semelhante, quando a razão de decidir é a mesma. Esse argumento ainda tem mais valor à vista da regra das Ordenações, Livro $4^{\circ}$, título II - que em favor da 
liberdade são muitas coisas outorgadas contra as regras gerais. Se em caso análogo e semelhante, tanto na espécie como no motivo, não cabe a regra da Ordenação citada, não há mais hermenêutica, e as leis devem ser casuísticas". Remetendo o processo ao despacho da princesa regente (D. Isabel ocupava pela segunda vez o trono do Império, enquanto o imperador Pedro II viajava pela Europa depois de ter representado o Brasil nas festas do primeiro centenário da independência dos Estados Unidos), o parecer acrescentava: "Vossa Alteza mandará o que for melhor". O despacho de D. Isabel foi o dássico "como parece" - ou seja, a aprovação do mesmo, datado do "Palácio do Rio de Janeiro, 20 de outubro de 1876". Encerrou-se, assim, a questão. Por falta de matrícula, adquiriram a liberdade os três escravos resendenses, pois que, muito embora o senhor deles, José Pereira da Silva Porto, houvesse ganho a ação ordinária, esta não produzira efeitos para o registro, por não ter havido apelação e, logo, não existir sentença confirmatória de segunda instância.

Quando dei conhecimento desse parecer de Machado de Assis ao jurisconsulto brasileiro Levi Carneiro, que foi um dos constituintes de 1934 e membro da Academia Brasileira de Letras, disse ele que, embora não sendo formado em direito nem em qualquer outra coisa - Machado de Assis demonstrara "uma clara consciência jurídica, um verdadeiro sentimento de justiça, uma perfeita compreensão do espírito da lei”. Foi depois de tal parecer que o ministro da Agricultura, Comércio e Obras Públicas, Tomás José Coelho de Almeida, efetivou Machado de Assis no cargo de chefe de seção, que ele exercia interinamente. Isso foi feito por decreto de 7 de dezembro de 1876, quando estava no poder o último gabinete presidido pelo senador Caxias (elevado a duque depois da guerra com o Paraguai). Com as novas responsabilidades e as vantagens financeiras decorrentes de sua efetivação em tal posto, pôde Machado de Assis deixar o cargo que exercia no Diário Oficial, consagrando-se daí por diante, como funcionário, apenas ao Ministério da Ag ricultura, Comércio e Obras Públicas, que ainda em vida dele começaria a ser desdobrado, dando origem a outras pastas - como a da Viação e a do Comércio.

Arranjou Machado de Assis outros meios de aumentar os seus proventos, passando a escrever romances folhetins para jornais, como O Globo e O Cruzeiro, ou para revistas, como a Revista Brasileira. Em O Globo, dirigido a partir do ano de 1874 por seu amigo Quintino Bocaiúva - que viria a ter grande evidência na República, como ministro das Relações Exteriores, deputado à Constituinte, senador e governador do Estado do Rio de Janeiro - publicou sucessivamente os romances $A$ Mão e a luva, em 1874, e Helena, em 1876. Em O Cruzeiro, que começou a circular em 1878, publicou o romance Iaiá Garcia. E, na Revista Brasileira, iniciou em 1880 a publicação do romance Memórias póstumas de Brás Cubas, uma de suas obras-primas, que se prolongaria de março a dezembro, saindo em volume no ano seguinte.

Por doze anos e quase quatro meses permaneceu Machado de Assis como simples chefe de seção, muito embora tenha exercido a função de oficial de gabinete de dois ministros, durante esse período. Quando, a 8 de março de 1880, passou a exercer o cargo de ministro da Agricultura, Comércio e Obras Públicas o engenheiro Manuel Buarque de Macedo, que se formara na Escola Politécnica do Rio de Janeiro e, em seguida, fizera em 
Paris um curso de aperfeiçoamento profissional, Machado de Assis foi por ele chamado para servir em seu gabinete. Mas pouco durou a gestão do ilustre eng enheiro. Ele morreu repentinamente a 21 de agosto de 1881, quando acompanhava o imperador D. Pedro II a Minas, na viagem destinada a inaugurar o ramal ferroviário de São João del Rei. Foi então designado para responder pela pasta vaga o deputado-geral fluminense Pedro Luís Pereira de Sousa, que era em caráter efetivo ministro dos estrangeiros. Assoberbado com o trabalho de duas pastas - a segunda ainda mais trabalhosa que a primeira -, Pedro Luís Pereira de Sousa confiou a Machado de Assis grande parte de suas tarefas na última. Durante os meses que se seguiram, Machado de Assis foi praticamente um vice-ministro. Era quem recebia, em nome do ministro, as pessoas brasileiras e estrangeiras que tinham interesse a tratar no seu Ministério. Quando o senador José Antônio Saraiva passou a ocupar a pasta, em caráter efetivo, Machado retornou a seu posto de chefe de seção.

Só a 30 de março de 1889, quando era ministro da Agricultura, Comércio e Obras Públicas o senador Rodrigo Augusto da Sirva, integrante do gabinete chefiado por João Alfredo Corrêa de Oliveira, que no ano anterior promovera a abolição total da escravatura, é que Machado de Assis foi novamente promovido. Passou, nessa data, a diretor de um dos departamentos em que se dividia o ministério. Seu título era o de diretor de Viação. Com a República, proclamada a 15 de novembro de 1889 , sua situação permaneceu inalterada. O primeiro ministro da Agricultura do novo regime, foi, em caráter interino, o seu velho amigo Quintino Bocaiúva, seu companheiro por vários anos na redação do Diário do Rio de
Janeiro e, mais tarde, diretor de O Globo, onde publicara dois romances. Quintino, que era o ministro efetivo das Relações Exteriores (novo nome do antigo Ministério dos Estrangeiros), pouco tempo depois entregou a segunda pasta ao ministro efetivo, Demétrio Ribeiro, que nela pouco demorou, sendo a 30 de janeiro de 1800 substituído por Francisco Glicério. Durante a gestão deste, Machado de Assis sofreu uma tentativa de ag ressão, por parte de outro funcionário, que, aliás, era também escritor - Luís Francisco da Veiga -, mas o ministro deu mão forte ao agredido. $\mathrm{O}$ assunto chegou a ser tratado numa das reuniões do chefe do Governo Provisório, marechal Manuel Deodoro da Fonseca, com seus ministros. Francisco Glicério disse ter determinado a suspensão de Luís Francisco da Veiga, que entretanto, não se conformara. Assim, propunha a aposentadoria imediata de Luís Francisco da Veiga. Tal proposta foi aprovada por unanimidade pelos presentes: Deodoro, Campos Sales, Eduardo Wandenkolk, Cesário Alvim, Benjamim Constant e o próprio Francisco Glicério (dois ministros tinham deixado de comparecer: Quintino e Rui Barbosa, que era o titular da Fazenda).

Machado de Assis sofreu, durante o último ano do governo do Marechal Floriano Peixoto, injustos ataques de um inimigo gratuito, o exaltado panfletário e agitador político Deocleciano Mártir, que então publicava um pequeno jornal intitulado O Jacobino. Pouco depois de encerrada a "revolta da esquadra", o exaltado verrineiro começou a estampar nos "a pedidos" dos jornais listas de pessoas que eram por ele apresentadas como "monarquistas impenitentes" e "adversários encapuzados do regime republicano", exigindo que todos os denunciados fossem afastados, quanto antes, do 
serviço público. Entre eles, além de Machado de Assis e de numerosos outros, estava o barão do Rio Branco, que então pertencia ao serviço consular e viria a ser um benemérito da República, além de ter sido quem, até hoje, exerceu por mais tempo o cargo de ministro das Relações Exteriores - nada menos de dez anos servindo nos governos de Rodrigues Alves, Afonso Pena, Nilo Peçanha e Hermes da Fonseca. Machado de Assis não respondeu às acusações de Deocleciano Mártir. Mas foi defendido por um "republicano histórico", Lúcio de Mendonça, sob o pseudônimo de Z. Marcas, na revista $A$ Semana, de Valentim Magalhães. Lúcio de Mendonça, que exercia importante cargo no Ministério da Justiça, fez ao mesmo tempo o elogio do escritor e do funcionário, ambos merecedores de consideração, estima e reconhecimento.

$\mathrm{Na}$ verdade assim era. Lúcio de Mendonça não citou, mas poderia ter citado casos específicos, em que Machado de Assis demonstrara seu espírito público, evitando que erros fossem cometidos pela administração, como no parecer sobre os escravos de Resende e episódios semelhantes. Um destes era bem recente.

Ocorrera dois anos antes, quando lavrara a grande crise financeira, que deu lugar às especulações do chamado "encilhamento". Em maio de 1892, quando o governo do marechal Floriano Peixoto ainda não havia completado um ano, Machado de Assis vira, no Diário Oficial, a publicação de um "relatório de invenção", firmado por um norte-americano, George Boyngton Boyngton, que dizia ter descoberto "um processo engenhosíssimo e inteiramente novo para a obtenção do capital necessário a um empreendimento qualquer". E acrescentava: "A idéia do inventor é aproveitar o bem conhecido espírito de especulação do povo, a fim de dirigir, a um destino novo e útil, o dinheiro empregado em especulações arriscadas". E adiante explicava que se tratava da "venda de cartões, em tal número e tal preço, que de seu produto, deduzidas as despesas, ficaria como lucro líquido o capital desejado." E ainda: "Exemplificando para maior clareza: dado que se precise, para uma empresa reunir o capital de 550:000\$, anunciava-se a venda de 200.000 cartões, a $5 \$$ cada um, o que produzirá 1.000:000\$. Dessa quantia há a deduzir: o desconto de $10 \%$ dos vendedores, 100:000\$; as despesas dos anúncios e outras, 20:000\$; os prêmios pagos em dinheiro, 330:000\$; 450:000\$. Restam os desejados 550:000\$, que constituem o capital da companhia, dividido em ação de $200 \$$ cada uma, das quais umas serão distribuídas por segundo sorteio e outras ficarão pertencendo ao inventor da distribuição sistemática"... Era uma arapuca, uma dupla loteria - e a patente já havia sido concedida, pelo Ministério da Fazenda, sob o número 1.140.

Machado de Assis, por puro espírito público, ainda que se tratasse de assunto de outro ministério, resolveu intervir para promover a cassação de tal patente, aprovada por inadvertência do jovem ministro da Fazenda, Inocêncio Serzedelo Correia. Em caso anterior, quando outra patente fora concedida, para outra loteria dissimulada, a anulação fora promovida por via judicial, pois que fora outorgada pelo Governo Provisório, que tinha poderes não só executivos, mas legislativos. De pois de ouvir o parecer da $2^{\text {a }}$ Seção da Diretoria de Comércio, Machado de Assis submetera o assunto à decisão do ministro da Agricultura, Comércio e Obras Públicas, Antão Gonçalves de Faria, pedindo que fosse promovida a anulação 
da patente de Boyngton. Apesar dos protestos de Boyngton, que ameaçou promover uma ação por perdas e danos, a Diretoria de Comércio, pela qual respondia Machado de Assis, obteve que o ministro interviesse, para anular a concessão, o que acabou sendo feito, por despacho de 8 de setembro de 1892, por se ter "transformado a concessão em loteria e em fonte de jogo". Lúcio de Mendonça não citou em defesa de Machado de Assis essa recente demonstração de zelo, mas condenou as maliciosas denúncias de Deocleciano Mártir, dirigindo-se a esse desabusado panfletário: "Com um nome, então, foi você caipora como nos seus piores dias: com o nome de Machado de Assis. Quem é este homem, sabem-no todos, menos talvez o Sr. Deocleciano Mártir. É um filho de si próprio, ex se natus, na enérgica expressão de Tácito; obscuro, artista anônimo, tipógrafo, depois revisor de provas, depois noticiarista, depois cronista e poeta, depois chefe incontestado da literatura brasileira. Apenas isto: uma reputação nacional, feita a pouco e pouco, passo a passo, dia a dia, na modéstia, na perseverança e no trabalho para o pão de cada dia, e no estudo e no esforço nobre para a conquista do saber e da glória. Se há um homem para honrar toda uma democracia moderna é este. Quem quer que tenha uma leve intuição de justiça, uma centelha de paixão republicana, há de venerar este homem. O Sr. Deocleciano Mártir apedreja-o. É medonho para você, jacobino".

Mais importante ainda que a defesa de Lúcio de Mendonça - que não tardaria a ser procurador geral da República em seguida, ministro do Supremo Tribunal Federal - foi a carta de agradecimento que o general Sérgio Bibiano da Fonseca Costallat - o último ministro da Agricultura,
Comércio e Obras Públicas do governo do marechal Floriano Peixoto - enviou a Machado de Assis na data em que deixou o poder. Nessa carta, louvou ele a ca pacidade e a diligência do funcionário Machado de Assis, dizendo que, sem o seu esclarecido auxílio e sem o seu profundo conhecimento dos negócios daquela pasta, com os quais, como militar, pela primeira vez lidava, não teria conseguido desempenhar-se a contento do cargo de ministro, a que fora levado pela confiança de Floriano.

Machado de Assis viria a sofrer, no governo do presidente Prudente de Morais, o que considerou uma grave injustiça. Julgando lhe ser agradável e querendo deixar-lhe mais tempo livre para seus trabalhos literários, o novo ministro, Sebastião Eurico Gonçalves de Lacerda pai do grande tribuno parlamentar Maurício de Lacerda e avô de Carlos Lacerda - resolveu substituir Machado de Assis na Diretoria de Viação, que então ocupava, deixando-o como simples "adido à Secretaria de Estado, percebendo os vencimentos que lhe competirem". Machado ficou muito magoado, achando que o ministro o julgara um inútil. Queixouse muito, em cartas aos amigos, não se conformando em ficar de braços cruzados, ganhando o dinheiro da nação sem trabalhar. Foi durante esse período que escreveu uma de suas obras-primas, Dom Casmurro; sempre demonstrara, em seus romances, contos e crônicas, profunda aversão aos parasitas. E era sincero. Não queria ser um deles. E não sossegou enquanto não voltou à atividade, embora diminuído funcionalmente: de diretor de um departamento, passou a ser simples secretário do ministro Severino Vieira. Quando este se demitiu, no governo de Campos Sales, para candidatar-se ao governo da Bahia, o ministro da Justiça, 
Epitácio Pessoa, nomeado para substituir interinamente Severino Vieira, não se deu bem com Machado de Assis. Jovem, irrequieto, Epitácio estava então veraneando em Petrópolis. Pela manhã, atendia ao expediente da pasta da Justiça. À tarde, ia para o outro Ministério, onde Machado de Assis lhe fazia minuciosas exposições sobre cada assunto, apresentando-lhe em seguida as minutas dos despachos. Epitácio queria sempre abreviar as exposições, a fim de não perder a barca que saía da Prainha para Mauá, no fundo da baía, de onde nos fins do século passado partia o trem para Petrópolis. Algumas vezes perdeu a barca, só tomando a segunda e chegando à casa já em plena noite. Por isso disse um dia, de Machado: "Grande escritor, mas péssimo secretário!" Talvez Machado, sem o dizer, pensasse a mesma coisa de Epitácio: "Moço inteligente, mas muito afobado para ser um bom ministro!"

Machado passou vários anos constrangido e humilhado até encontrar, em Lauro Müller - o grande ministro da Viação que iniciou as obras do Porto do Rio de Janeiro e fez construir a avenida Central, hoje avenida Rio Branco - quem lhe fizesse justiça. Lauro Müller fez Machado voltar a ser diretor. E diretor-g eral de Contabilidade. O sucessor de Lauro Müller, Miguel Calmon, a 16 de dezembro de 1907, aumentou ainda mais suas responsabilidades, nomeando-o juntamente com Luís Rodolfo Cavalcanti de Albuquerque (diretor das Rendas Públicas do Tesouro Nacional) e com o engenheiro Francisco Bicalho, para exercer as funções de membro da Comissão Fiscal e Administrativa das Obras do Porto do Rio de Janeiro, sem prejuízo de suas funções de diretor-geral de contabilidade.
Machado de Assis morreu no ano seguinte, a 29 de setembro, com 69 anos de idade e com 40 anos e cinco meses de serviço público. Morreu sem ter se aposentado, porque teve a preocupação de ser útil à pátria, enquanto teve forças para tanto.

Seus funerais foram custeados pelo governo federal e o Ministério da Viação, Indústria e Obras Públicas, em que ele trabalhava (o da Agricultura já tinha então existência à parte). $\mathrm{O}$ expediente da Diretoria Geral de Contabilidade foi encerrado ao meio-dia, para que os funcionários subordinados a Machado de Assis pudessem comparecer ao enterro, que saiu do Silogeu Brasileiro, à rua Augusto Severo, onde então a Academia Brasileira de Letras tinha a sua sede. O senador Rui Barbosa, membro da Academia, discursou na saída do enterro. Falaram, no Senado, o senador Érico Coelho e, na Câmara, o deputado Alcindo Guanabara, fazendo o seu elogio. O presidente Afonso Pena, que morreria no ano seguinte, transmitiu à Academia Brasileira de Letras este telegrama: "Apresento a essa ilustre corporação os meus sinceros pêsames pelo falecimento de seu preclaro presidente, Machado de Assis, glória da literatura brasileira".

Todas essas homenagens - e muitas outras, que seria longo enumerar-se - dirigiam-se, é claro, ao escritor que, nos seus últimos anos de vida, culminara sua atividade com a publicação de alguns dos seus mais notáveis livros - os romances Dom Casmurro, Esaú e Jacó e Memorial de Aires e as narrativas curtas das Várias histórias, dos Papéis avulsos e das Relíquias de casa velha. Porque também nas letras, como na função pública, não se aposentou. E só largou a pena quando a morte o venceu. 
Raymundo Magalhães Júnior

Jornalista e bióg rafo, nasceu no Ceará em 1907 e faleceu no Rio de Janeiro em 1981. Ingressou na Academia Brasileira de Letras em agosto de 1956, ocupando a Cadeira n 34, sucedendo a D. Aquino Correia. 